\title{
"What the weather will do" - results of a survey on impact-oriented and impact-based warnings in European NMHSs
}

\author{
Rainer Kaltenberger, Andreas Schaffhauser, and Michael Staudinger \\ Zentralanstalt für Meteorologie und Geodynamik (ZAMG), Vienna, Austria \\ Correspondence: Rainer Kaltenberger (rainer.kaltenberger@zamg.ac.at)
}

Received: 1 March 2020 - Accepted: 12 March 2020 - Published: 31 May 2020

\begin{abstract}
European NMHSs are progressing from warnings based on fixed thresholds or climatology-based thresholds to impact-oriented and impact-based warnings. This publication gives an overview of warning implementation as surveyed at 32 of the 37 NMHSs participating in the EUMETNET Meteoalarm project. The report addresses these topics: warning format, legislation and production process of warnings, dissemination and verification of warnings, impact databases, warning strategy and cooperation, legal obstacles and cross-border collaboration. Potential obstacles are identified and possible trends are discussed.
\end{abstract}

\section{Introduction}

The Sendai Framework for Disaster Risk Reduction 20152030 (United Nations, 2015) states, that the implementation of effective disaster risk reduction measures should be based on understanding of all aspects of disaster risks, establishing a basis for a paradigm shift of national meteorological and hydrological services (NMHSs) in their warning decision process towards user-oriented, impact-based warnings (IbWs). The risk of a hydrometeorological event can be represented by the relationship

Risk $=$ Hazard $\times$ Vulnerability $\times$ Exposure.

It is worth noting that the spatiotemporal climatology of a hazard is implicitly driving all three terms in this relationship. This means that proper analysis of spatiotemporal climatology plays an essential role as NMHSs progress towards IbWs. The climatological return period of a hazard, for example, is related to socio-economic vulnerability of a location, which is in turn influenced by specific policies such as land use zoning or building codes.

A user-oriented and meaningful hydrometeorological warning addresses "What the weather will do" rather than "What the weather will be". In a Sendai Framework context such a warning, which we propose to call "impact-oriented warning" (IoW), should have both a tangible and under- standable description of an expected damage scenario (information on impacts) and clear advice on what to do (instructions/advisories). An example of an IoW is shown in (Fig. 1). As the term IoW refers to a content wise structure of a warning, it is independent of the production process of issuing a warning, or the criteria of a warning, which may be threshold-based or impact-based. Impact-based warnings can be generated subjectively, e.g. by discussing impacts of a forecasted event with stakeholders or expert partners, or objectively via sophisticated impact-models using vulnerability and exposure datasets as well as meteorological information (WMO, 2015). The objective approach requires a comprehensive understanding of all risk factors of a user group. The transition from IbW to impact warnings, which are based on individual user criteria (e.g. derived from social profiling), is gradual. Proper terminology is of high relevance.

A growing number of initiatives and re-users collect authoritative warning information on a global level. They use the WMO Register of Alerting Authorities (WMO, 2020d) and incorporate this information into products and services, such as the WMO Severe Weather Information Centre visualization (SWIC; WMO, 2020c; Tong and Cheng, 2018) as part of the WMO Global Multi-hazard Alert System framework (GMAS; WMO, 2019) or the Filtered Alert Hub initiative (Christian, 2020). These initiatives and re-users work best when warning information is harmonized. In ad- 


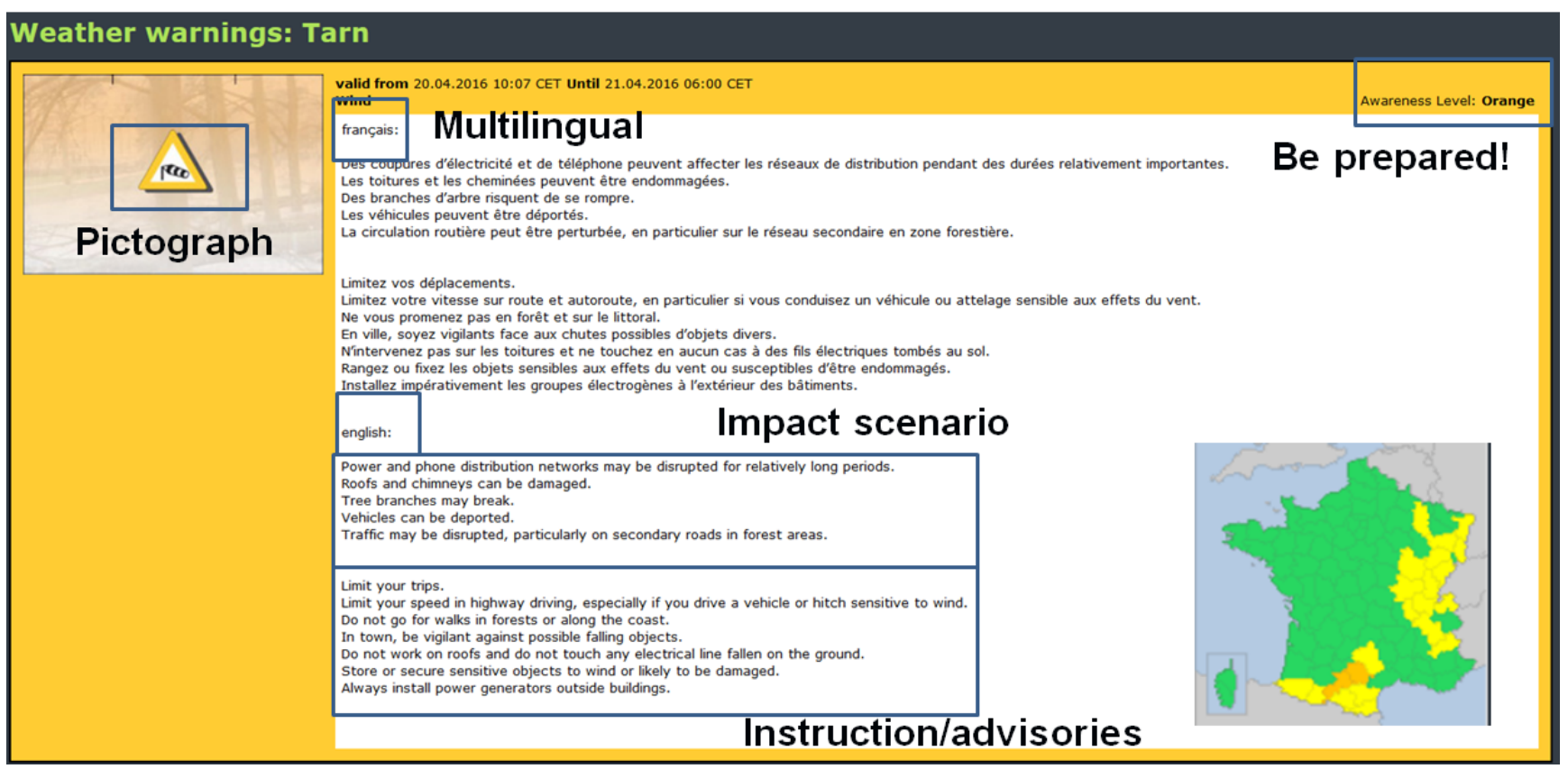

Figure 1. Example of an impact-oriented warning from Météo-France targeting the general public and addressing "What the weather will do", taken from Meteoalarm (http://meteoalarm.eu, last access: 24 April 2020). As the warning has a tangible and understandable description of an expected damage scenario (information on impacts) and clear advice on what to do (instructions/advisories) it is in alignment with the Sendai Framework.

dition to alignment with the Sendai Framework, the messages should be compliant with the international standard Common Alerting Protocol (CAP) designated as ITU Recommendation X.1303. CAP is a standardized XML format for emergency alerting (OASIS, 2020a) and is endorsed as a standard technical format of warnings by ITU, WMO, and IFRC, among other international institutions. CAP is also used by a growing number of global re-users of authoritative warning information (Christian, 2019) such as Google Crisis Response, IBM/The Weather Company, AccuWeather, MeteoGroup, and Windy.com, among others. Harmonized structures of content and standardized formats are also implied by WMO Resolution 40 (Cg-XII; WMO, 1995), requesting NMHSs to provide "Severe weather warnings and advisories for the protection of life and property targeted upon endusers" on a "free and unrestricted basis" and that "warnings and forecasts relevant to the safety of life and property publicly issued by the commercial sector should be consistent with those originated by NMSs or by other official originators".

From August 2018 to May 2019 a survey, consisting of 79 items, was conducted on the status of implementation of IoWs and IbWs, with attention to: warning format, legislation and production process of warnings, dissemination and verification of warnings, impact databases, warning strategy and cooperation, legal obstacles and cross-border collaboration. The survey was carried out among 37 NMHSs participating in the EUMETNET EMMA/Meteoalarm project, an integrated, regional warning system currently supporting 33 languages and 12 hazards to visualize warnings from $\mathrm{Eu}-$ ropean NMHSs in an easy and understandable way and make them available to re-users (EUMETNET, 2020a, b; Dupuy et al., 2011).

Responses to the survey were received from 32 of those 37 (86\%) NMHSs (Fig. 2). The final results were presented at the EUMETNET IoW/IbW workshop in Vienna in June 2019 and at the EMS Annual Meeting 2019 in Copenhagen in September 2019.

\section{Warning format, legislation and production process of warnings}

The survey found that $41 \%$ of NMHSs are issuing IoWs on their website, $28 \%$ are issuing IoWs for some parameters and $28 \%$ are not issuing IoWs. On Meteoalarm.eu, $34 \%$ or NMHSs are publishing IoWs, $34 \%$ are issuing IoWs for some parameters and $41 \%$ are not issuing IoWs. Warnings from $38 \%$ of NMHSs contain a tangible and understandable description of a damage scenario/impact-scenario, $22 \%$ are not yet there and $34 \%$ see such a descriptive task as within the purview of a separate authority.

$75 \%$ of the surveyed NMHSs do not see legislative reasons preventing them from issuing IoWs or IbWs, but $17 \%$ are facing legal obstacles such as this responsibility being placed within civil protection authorities (CPAs) or other authorities (Fig. 3). Regarding warning products, $94 \%$ are is- 


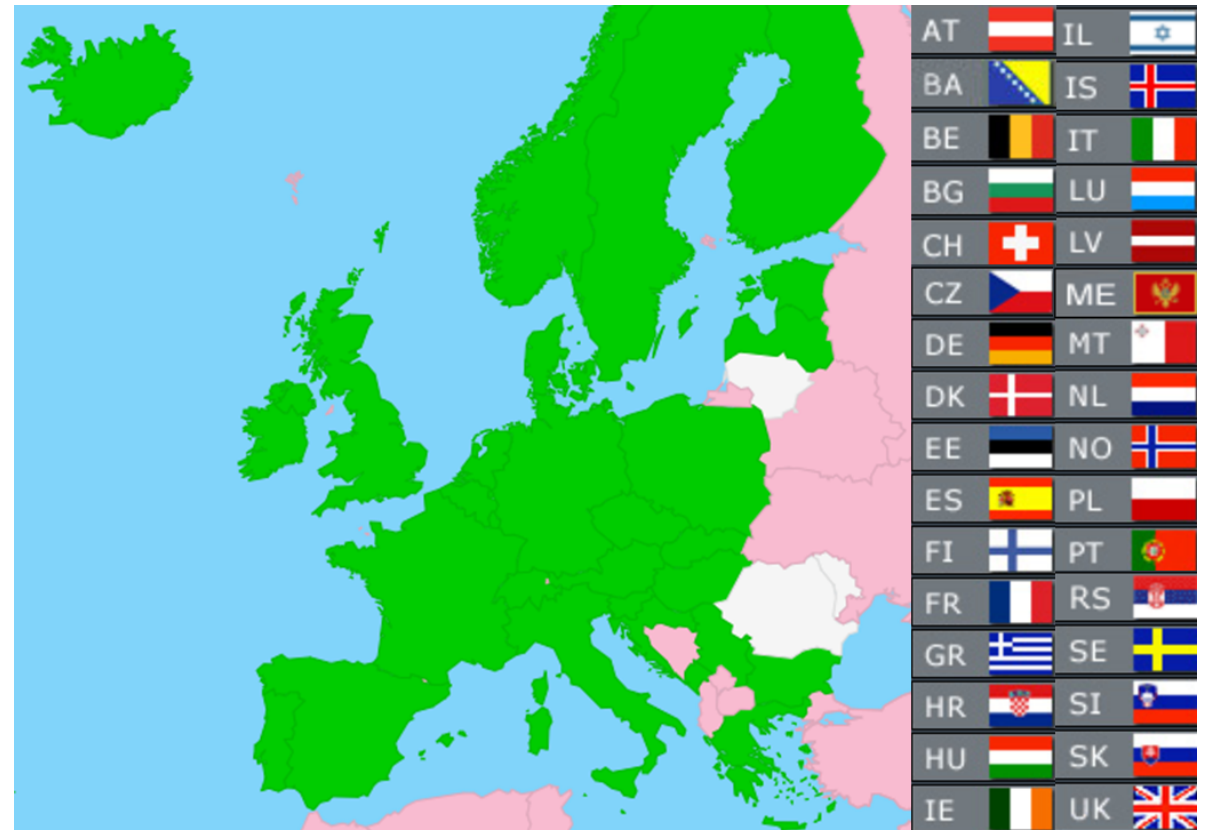

Figure 2. 32 (marked in green) of 37 (86\%) NMHSs, participating in the EUMETNET EMMA/Meteoalarm project, responded to 79 questions within a survey on impact-oriented and impact-based warnings, carried out from August 2018 to May 2019.

suing warnings, $50 \%$ are issuing warning outlooks and $9 \%$ are issuing other warning products. The survey found: $34 \%$ of European NMHSs do have legislative definitions of warnings, watches, outlooks, and the like; $56 \%$ do not have such definitions; $9 \%$ are using pictographs to describe the expected impacts or advisories; $63 \%$ are not doing it; and, $28 \%$ are planning to do so.

The survey found that a four-level color code (green, yellow, orange, red) is well established: $84 \%$ of NMHSs are using it on their webpage; only 2 of the 37 NMHSs participating in the EMMA/Meteoalarm Program are using a five-level color code.

Regarding the zoning of warnings the survey found: a majority, $53 \%$ of NMHSs, are issuing warnings on district level; $25 \%$ are using free polygons (consisting on latitude/longitude pairs); $19 \%$ are issuing warnings on municipality level; $9 \%$ are issuing warnings on state level; and, $22 \%$ are doing it another way. There is a clear trend concerning the use of free polygons in the future: a majority of $56 \%$ are planning to issue their warnings in this way; $31 \%$ do not know and $9 \%$ are not planning to do so.

Asked whether NMHSs are including a quantitative estimation of the certainty (likelihood) of the event into public weather warnings, a majority of $41 \%$ replied "No", $28 \%$ answered "Yes" and $22 \%$ responded "Not yet, we are planning to do so".

Regarding languages, $50 \%$ of European NMHSs are currently issuing warnings in one language, $38 \%$ are supporting two languages, $9 \%$ are publishing warnings in three languages and one NMHS features four languages (excluding regional dialects and co-official languages). Warnings in English are issued by 14 of the 32 NMHSs on their webpage. On Meteoalarm, warnings are currently published in 33 different languages. The vast majority, $81 \%$ of NMHSs, support English warning texts. On the matter of how forecasters translate warnings: $47 \%$ of NMHSs are using static text for each warning parameter/warning; $28 \%$ of NMHSs translate warning texts individually by forecasters; and, $6 \%$ translate warning texts individually by other staff.

Regarding the production process of public weather warnings five years ago, now and five years from now (Fig. 4), most European NMHSs are currently in transition to impactbased criteria from fixed thresholds $(31 \%)$ or climatologybased thresholds, which are currently used by the majority $(66 \%)$ of NMHSs. As the main criteria for warning decision of public weather warnings five years from now: $50 \%$ of NMHSs expect to use subjective impact-based criteria, $47 \%$ expect to use objective impact-based criteria, $44 \%$ expect to use climatology-based criteria, and $9 \%$ expect to remain with fixed thresholds.

Asked whether quantitative thresholds for each warning level made publicly available on your website, $47 \%$ replied "Yes, for all parameters", $6 \%$ selected "Yes, for some parameters" and $38 \%$ answered "No". Questioned whether warning decision criteria for each warning level are made publicly available on their website, $25 \%$ replied "Yes, for all parameters", $6 \%$ answered "Yes, for some parameters" and $56 \%$ ticked "No". A majority of $69 \%$ of European NMHSs, currently do not run impact models for the production of IbWs. Only one NMHS answered "Yes, for all warning parame- 
Do you have legislative definitions of warnings, watches, outlooks etc. ?

Yes

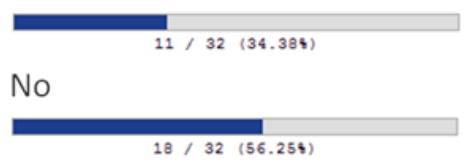

Do legislative reasons prevent you from issuing impactoriented or impact-based warnings?

No

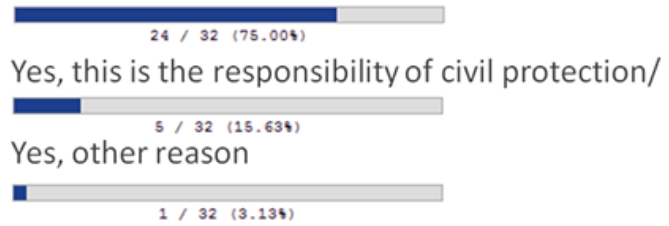

Figure 3. Legal aspects of warnings. $75 \%$ of the surveyed NMHSs do not have legislative reasons preventing them from issuing impactoriented or impact-based warnings. However obstacles are identified in fragmentation of responsibilities of authorities, fears of CPAs to "lose control" in the decision process, federalization and high number of authorities involved, as well as cooperation to CPAs and other authorities, among others.

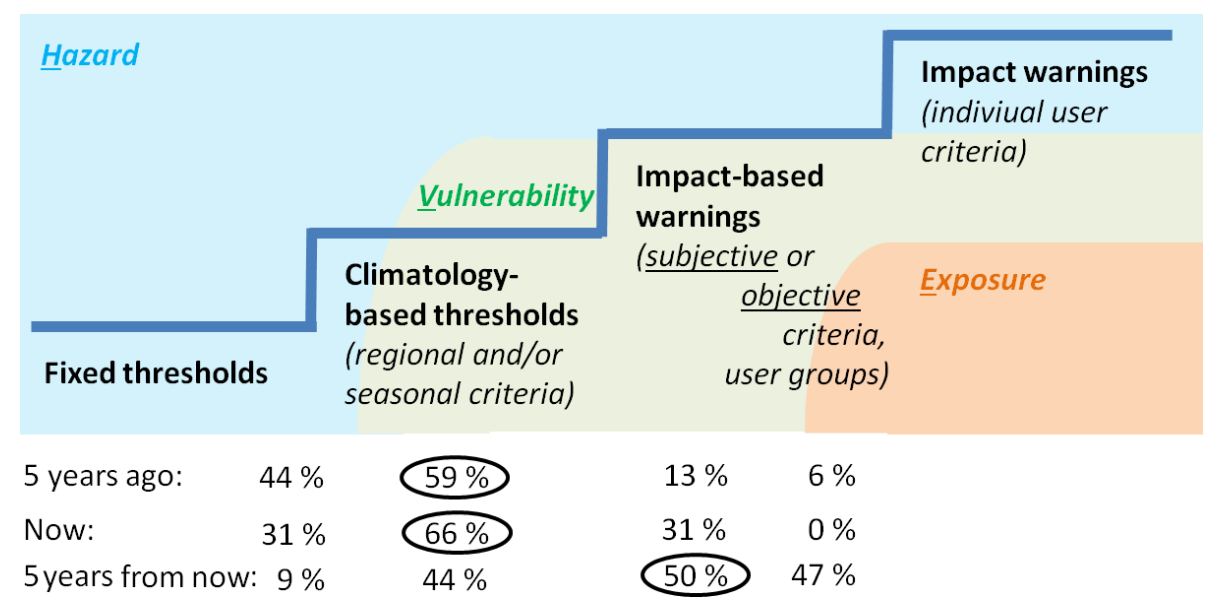

Figure 4. Evolution of public weather warnings, incorporating information on hazard, vulnerability and/or exposure. Warning criteria used at 32/37 European NMHSs participating in the EUMETNET Meteoalarm project 5 years ago, now (2018/2019) and 5 years from now. Maximum values marked with an ellipse. European NMHSs are currently in the transition phase from fixed thresholds or climatology-based thresholds to impact-based warnings based on subjective or objective criteria.

ters", another one answered "Yes, for some warning parameters" and $25 \%$ said "Not yet, we are planning to do so".

In the comment section of the questionnaire, models targeting thunderstorm-related wind gusts, vehicle overturning and flood forecasting were named. Asked how impactbased thresholds/criteria are assessed a vast majority, $94 \%$, replied "forecasters experience", $44 \%$ of NMHSs replied "In-house studies" followed by post-disaster assessment together with CPAs ( $38 \%$ ), media monitoring ( $34 \%$ ), feedback from costumers $(30 \%)$, studies together with external organizations (20\%), studies including expert advice of authorities of neighboring disciplines (20\%), in-house modeling $(10 \%)$, studies together with private companies and modeling including expert advice of authorities of neighboring disciplines (3\%), $13 \%$ ticked "other" and mostly mentioned feedback from emergency services like fire brigades in the comments.

A relative majority of NMHSs $(47 \%)$ currently do not have research cooperations in the field of impact modeling, $31 \%$ replied "Not yet, we are planning to do so" and just
$16 \%$ do have cooperations in that field. The question "How do you leverage results from impact studies into your daily warnings?" was answered with "raise awareness/training of forecasters" (53\%), adapting existing thresholds/criteria (44\%), adopt guidelines/SOPs (19\%), implementing in impact models $(3 \%)$ and "Other" $(6 \%)$. How do you assess vulnerability in this context? $44 \%$ replied "manually by incooperating damage reports of already impacted regions", $28 \%$ selected "population density" and "risk/hazard maps (e.g. flooding, landslides)" respectively, one NMHS chose "vulnerability models" and 9\% named "other". Questioned whether NMHSs are issuing IbWs according to different user groups, $34 \%$ said "Yes", $31 \%$ replied "No" and $13 \%$ selected "Not yet, we are planning to do so". NMHSs were further asked to name these user groups; predominant answers were road maintenance, CPAs, fire brigades, ports and electricity operators.

Severe thunderstorm warnings are predominantly produced manually (78\% of NMHSs), $6 \%$ are using semiautomatic methods, $9 \%$ of NMHSs are generating severe 


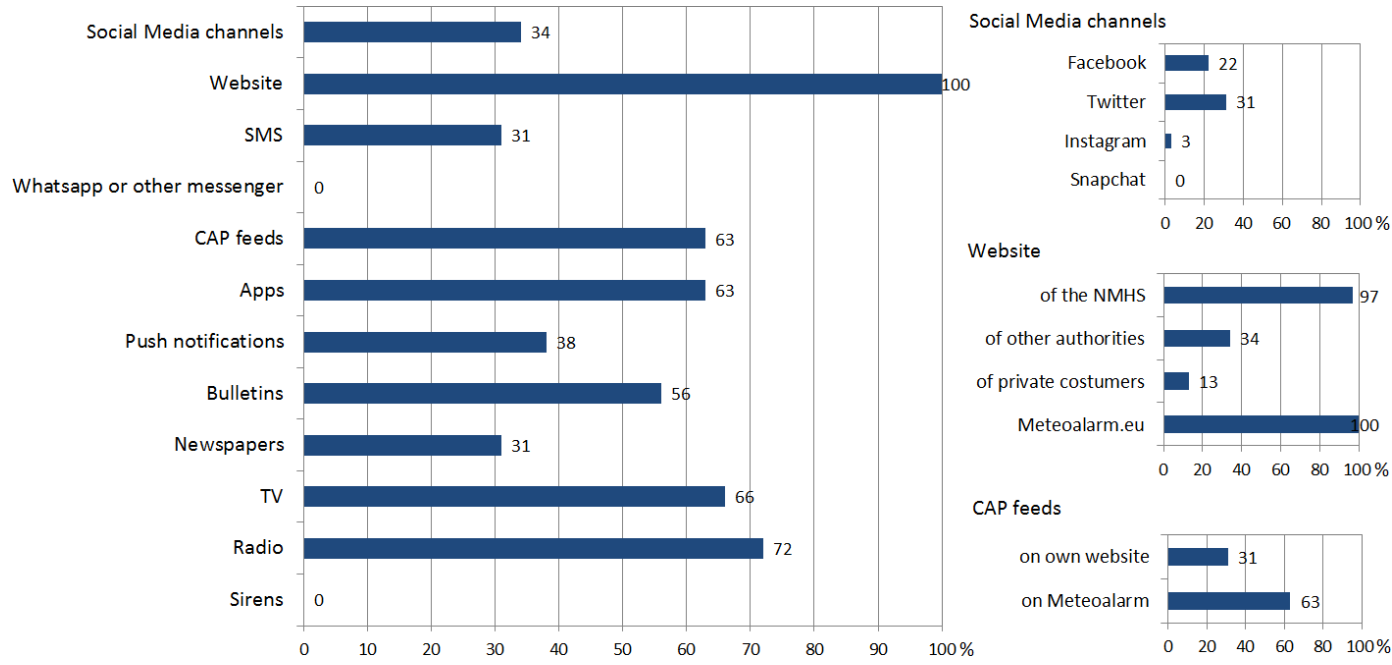

Figure 5. Dissemination channels regularly used for hydrometeorological warnings as surveyed at 32 of the 37 NMHSs participating in the EUMETNET Meteoalarm project. Further regular dissemination channels include email, ftp, YouTube and podcast/MP3.

thunderstorm warnings automatically and $9 \%$ do not issue such warnings. Criteria for the issuance of severe thunderstorm warnings include damaging wind gusts $(88 \%)$, large hail $(81 \%)$, flash floods $(78 \%)$, lightning $(50 \%)$ and tornadoes $(31 \%)$.

NMHSs were further asked to briefly describe their current warning criteria for extreme temperature warnings: a majority of NMHSs in Europe are using static thresholds or climatology-based criteria with a broad range of different parameters and methods, e.g. derived from heat wave criteria (exceedance of thresholds for a number of consecutive days). Some NMHSs are using perceived temperature or physiologically equivalent temperature (PET), bio-meteorological indices or are incooperating results from mortality studies.

\section{Dissemination of warnings}

Regular warning dissemination channels of European NMHSs (Fig. 5) include social media (34\%); more specifically Facebook (22\%), Twitter (31\%) and Instagram (3\%) are being used, while Snapchat is not being used. A vast majority $(97 \%)$ are using their own website to publish warnings, $34 \%$ of NMHSs regularly disseminate warnings on websites of other authorities and $13 \%$ warnings publish their warnings on websites of private costumers. $100 \%$ of participating NMHSs are publishing warnings on Meteoalarm. $31 \%$ of NMHSs are using SMS as a regular dissemination channel of warnings, whereas WhatsApp or other messengers are not being featured. $31 \%$ of NMHSs are publishing warnings via CAP feeds on their website ( $28 \%$ or $9 / 32$ via RSS, $9 \%$ or $2 / 32$ using ATOM), whereas $63 \%$ are disseminating warnings via CAP feeds on Meteoalarm. $63 \%$ are furthermore using (mobile) apps as a regular dissemination channel, while $38 \%$ are featuring push notifications. $56 \%$ are publish- ing warnings via bulletins exchanged with other authorities $(50 \%)$ or private costumers $(28 \%)$. Further regular dissemination channels of warnings include newspapers (31\%), TV $(66 \%)$ and radio (72\%); sirens are not being used. Other answers included email, ftp, YouTube and podcast/MP3.

To the question "On which type of media are your warnings published in extremely dangerous situations which require to act immediately?" $53 \%$ responded, that this is the responsibility of CPAs/another authority. Apart of that mostly all of the aforementioned dissemination channels are being used, with a slight increase in the items social media (44\%), more specifically Facebook (32\%) and Twitter (38\%), TV $(72 \%)$, radio (78\%), SMS (44\%) and WhatsApp (3\%). Two third of NMHSs ( $66 \%$ ) are currently not addressing needs of disabled persons regarding publication of warnings, whereas around one third (31\%) have taken measures such as barrier free webpages, e.g. using warning maps suitable for visually impaired, sign language or warnings in MP3 format.

\section{Verification of warnings and impact data}

$97 \%$ of the surveyed NMHSs see crowdsourced weatherand impact observations as important for operational meteorologists to have them available in real-time "to see what's happening out there", $88 \%$ agree, that they are important, because they have the potential to close the gap of "ground truth", and $78 \%$ see them important for the verification of IoWs/IbWs (Fig. 6). $44 \%$ regard them as important in view of the decreasing number of weather observations through observers. Is the number of weather observations through official weather observers (SYNOP, climate observations) in your country decreasing? $47 \%$ replied "No" and $44 \%$ replied "Yes". However, viewed on a map, it becomes obvious, that significantly more than a half of the European 


\section{I see crowdsourced weather- and impact observations as}

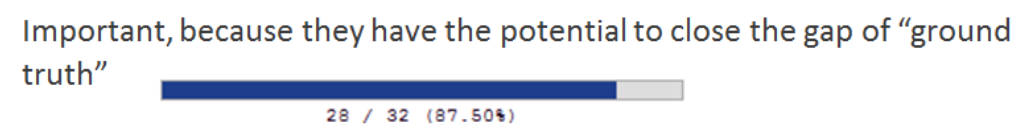

Important due to the decreasing number of weather observations through observers

$14 / 32(43.758)$

Important for the verification of impact-oriented-/impact-based warnings

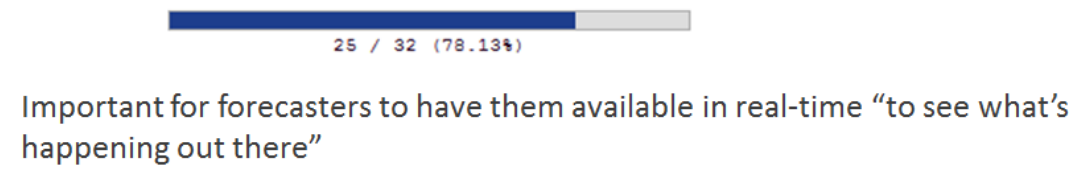

$31 / 32(96.888)$

Figure 6. Opinions regarding crowdsourced weather- and impact observations of 32/37 respondents. Crowdsourcing is seen as an appropriate way to close the gap of "ground truth" and important for the verification of IoWs/IbWs. Especially the real-time availability to "see what's happening out there" in order to adapt warnings in terms of a feedback loop is considered to be important for operational meteorologists.

territory is facing a decrease of official, human weather observers.

Asked whether the respective NMHS verify their IoWs or IbWs: $34 \%$ do it on a regular basis; $31 \%$ do it, but just for high-alert levels/red warnings; and $25 \%$ do not verify their IoWs or IbWs. How are IoWs or IbWs verified? $66 \%$ are using observations from automatic weather stations; $53 \%$ are using feedback/data from civil protection or other emergency authorities; $47 \%$ are using reports on social media; $38 \%$ are using feedback/data from other partnering institutions (e.g. road maintenance services), $19 \%$ are using other crowdsourced information like Trusted Spotter reports, the European Severe Weather Database (ESWD; Dotzek et al., 2009; ESSL, 2020b) or reporting apps. Other answers included TV and newspaper reports, eyewitness reports, hail suppression system reports, maps of call outs for emergency authorities and post-disaster assessment through site surveys. In order to receive weather- or impact observations/data, NMHSs are cooperating with CPAs $(63 \%)$, fire brigades ( $34 \%)$, the general public (34\%), other emergency authorities $(25 \%)$, spotter organizations $(19 \%)$ and other parties (6\%, including media and insurance companies).

A vast majority ( $78 \%$ ) of forecasters on shift are using images or videos posted in social media or other channels to see "what's happening out there", just $13 \%$ are not making use of those sources of information. More specifically, $13 \%$ are of NMHSs are using weather or impact observations posted on social media on a regular basis to validate/verify their warnings, $56 \%$ are doing it sometimes and $31 \%$ are not using them. Asked whether forecasters on shift adapt issued warnings according to the reported impact (feedback loop), a majority of $78 \%$ answered "Yes, sometimes", $6 \%$ replied "Yes, on a regular basis" and $9 \%$ responded "No".
A majority of $63 \%$ of NMHSs are currently not systematically collecting impacts in terms of an in-house impact database; $25 \%$ are doing so. Questioned which types of data this impact database contains, $28 \%$ answered "data provided by emergency authorities", $19 \%$ replied "media reports", $9 \%$ are storing impact observations from spotter organizations and $13 \%$ are collecting other types of human impact observations. Do NMHSs cooperate with other authorities in the field of impact-databases? Just $19 \%$ do so, a majority of $75 \%$ do not cooperate. Asked whether European NMHSs using ESWD data to verify/validate their warnings, $22 \%$ replied "Yes", $63 \%$ responded "No" and $9 \%$ ticked "I don't know".

$38 \%$ of institutes are sometimes carrying out post-disaster damage assessment in terms of field surveys whereas $47 \%$ are not doing it. If you carry out field surveys, which type of damage do you assess? Nine NMHSs are assessing damage caused by a tornado, eight are carrying out windstorm damage assessments, seven do flash flood damage assessments, five do riverine flood damage assessments, five are investigating damage due to avalanches, five are carrying out hail damage surveys, two having experience with lightning damage assessment or another type of damage (storm surge, earthquakes and volcanic eruptions) and one ticked "Soil/erosion/landslide damage". Do you collect reports/observations of rare meteorological phenomena, such as ball-lightning? $9 \%$ replied "Yes, in a database", $19 \%$ responded "Yes, but not in a coordinated way" and $63 \%$ said "No".

\section{Warning strategy and national cooperations}

Do you have a national strategy/national hazards partnership to implement IoWs/IbWs? Just $16 \%$ of surveyed NMHSs 
Do you have a national strategy/national hazards partnership to implement impact-oriented/impact-based warnings?

Yes

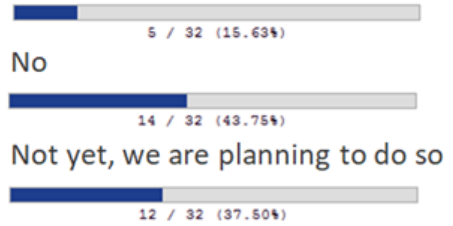

In your NMHS: Do you have an in-house strategy/roadmap to implement impact-oriented/impact-based warnings?

Yes

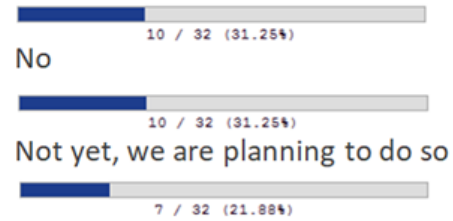

Figure 7. A majority of surveyed NMHSs currently do not have a national strategy/national hazards partnership to implement IoWs/IbWs. Slightly more NMHSs do have an in-house strategy/roadmap to implement IoWs/IbWs, others are planning to do so.

replied "Yes", $44 \%$ answered "No" and $38 \%$ responded "Not yet, we are planning to do so" (Fig. 7). Asked whether NMHSs have an in-house strategy/roadmap to implement IoWs/IbWs, $31 \%$ replied "Yes", $31 \%$ responded "No" and $22 \%$ said "Not yet, we are planning to do so".

Answers to the questions "Which challenges do you encounter in this field?" and "Where do you see possible pitfalls/handicaps in developing such strategies/national hazards partnerships?" were quite diverse, and can be categorized into legislative and organizational issues (e.g. fragmentation of responsibilities of authorities, fears of CPAs to "lose control" in the decision process, federalization and high number of authorities involved), cooperation with CPAs and other authorities, lack of resources (inadequate financial funding and shortage of interdisciplinary trained personnel/specialists), diversity of user needs (including understanding of the general public) and lack of (objective, realtime) impact data, impact-databases and standardized technical formats.

Regarding warning instructions/behavioral advisories, $72 \%$ do have cooperations or include expert advice from CPAs, whereas $13 \%$ replied "No" and 9\% responded "Not yet, we are planning to do so". $53 \%$ do have cooperations or include expert advice from authorities of neighboring disciplines (e.g. avalanche services, hydro services), while $28 \%$ answered "No" and $13 \%$ replied "Not yet, we are planning to do so". Just $6 \%$ of NMHSs are including expert advice from social scientists into their warning instructions/behavioral advisories, a prevailing majority of $63 \%$ ticked "No" and $22 \%$ responded "Not yet, we are planning to do so". Other public or private organizations dealing with security/security advices are approached by $41 \%$ of NMHSs, whereas $38 \%$ responded "No" and $13 \%$ replied "Not yet, we are planning to do so".

What type of interaction does your institute have with emergency authorities/CPAs before and during a high impact weather situation/red warning? A vast majority of $97 \%$ are having telephone calls followed by email (81\%), teleconferences $(59 \%)$, warning bulletins $(56 \%)$ and conferences (38\%). Other types of interactions include participation in a crisis team, embedded advisors and a web-based situational awareness platform.

\section{Cross-border collaboration}

NMHSs were asked to rate their current practice in exchanging information with neighboring NMHSs in case of crossborder high-impact weather situations: Just $6 \%$ replied "very good", $16 \%$ rated it as "good", $13 \%$ answered "OK", $25 \%$ replied "Could be better", $9 \%$ ticked "Could be much better" and $25 \%$ said "We don't have something like that". A number of NMHSs commented that the Meteoalarm webpage is their only exchange of information with neighboring countries at the moment.

Do you have Standard Operating Procedures (SOPs) to get in touch with a neighboring NMHS in case there is a cross-border high-impact weather situation? $28 \%$ replied "Yes", 19\% said "No, but we are working on that", $38 \%$ ticked "No, we don't have any such plans" and one NMHS is not allowed to get in touch with neighboring NMHSs due to legislative reasons (Fig. 8). Questioned which kind of interaction NMHSs have with neighboring countries before, during or after a cross-border high-impact weather situation, $31 \%$ replied "Forecaster telephone calls", followed by "None" (28\%), forecaster (web)conferences ( $9 \%)$, other (9\%, mostly contact via email was mentioned) and exchange of impact reports or joint post-disaster assessment ( $3 \%$ each). What are/would be your preferred ways to get in touch with forecasters from neighboring NMHSs in case of a cross-border high-impact weather situation? A majority of $50 \%$ replied "Chat-like tool", $44 \%$ preferred "phone calls", $31 \%$ responded "email", $22 \%$ replied "Message board (forum)", $16 \%$ answered "Video meeting" and one NMHS ticked "other".

At which stage would you like to get in contact with forecasters from neighboring NMHSs in case of a cross-border high-impact weather situation? $13 \%$ replied " $72 \mathrm{~h}$ or longer before the event", $25 \%$ said " $48 \mathrm{~h}$ before the event", a majority of $53 \%$ would like to get in touch $24 \mathrm{~h}$ before the event, $34 \%$ chose " $12 \mathrm{~h}$ before the event", $38 \%$ answered " $6 \mathrm{~h}$ before the event", $47 \%$ like to get contact forecasters from 
Do you have Standard Operating Procedures (SOPs) to get in touch with a neighboring NMHS in case there is a cross-border high-impact weather situation?

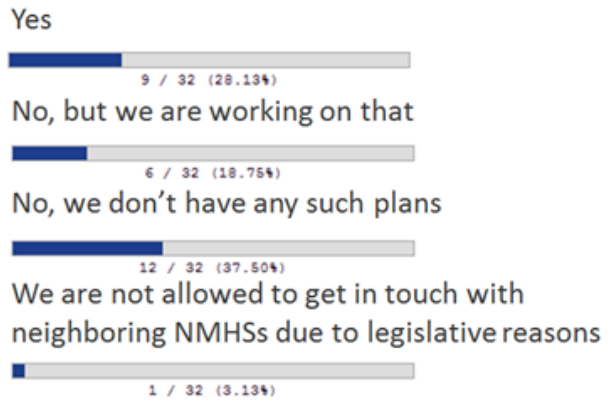

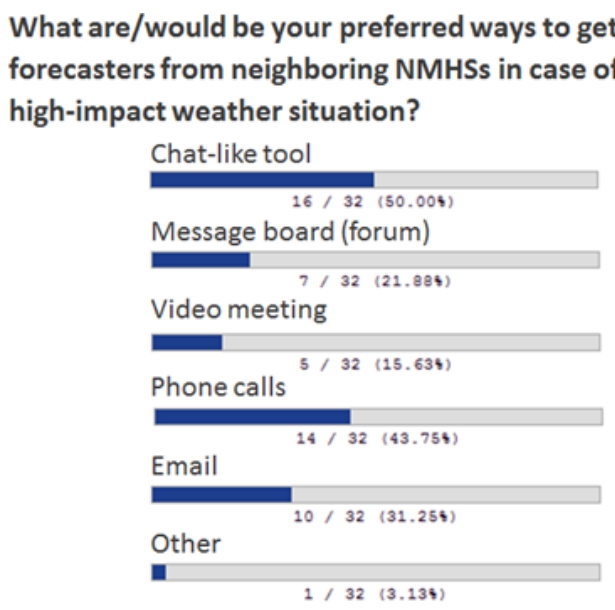

Figure 8. Results on questions regarding collaboration with neighboring NMHSs in case of a cross-border high-impact weather situations. There is room for improvement in establishing SOPs. Most of the operational meteorologists want to get in touch via chat-like tool or via phone call $24 \mathrm{~h}$ prior to the event.

neighboring NMHSs during the event and $31 \%$ responded "After the event".

\section{A last set of questions}

For the last set of questions, participants were asked to indicate whether they agree or disagree with a set of statements: the majority $(66 \%)$ of the participants agreed, that many NMHSs cannot afford to run impact models because they do not have the necessary IT infrastructure/expertise; $63 \%$ support the idea, that it is important to include expert advice from social sciences into IoWs/IbWs; $78 \%$ endorse the statement, that a quantitative estimate of likelihood/uncertainty needs to be part of warnings for the general public; $50 \%$ of participants agree, that technical standards are needed to exchange cross-border impact data; $56 \%$ think a standardized catalogue of weather- and impact reporting parameters will be necessary to exchange crowdsourced data internationally. A vast majority of $81 \%$ agree, that forecasters will always have the last voice in the warning decision whereas $38 \%$ do see warnings being mostly automatized within the next decade.

\section{Conclusions}

Around two third of European NMHSs are currently issuing impact-oriented warnings, i.e. warnings in a format describing "What the weather will do". $20 \%$ to $30 \%$ are facing legal obstacles or seeing it as a task of another authority. Regarding the production process of warnings/warning criteria, most of European NMHSs are currently in the transition phase from climatology-based thresholds to impact-based criteria. It is worth noting, that climatology is implicitly contributing or driving all terms of the risk of a hydrometeorological event
(Sect. 1). Two third of respondents think that many NMHSs cannot afford to run impact models, because they do not have the necessary IT infrastructure/expertise. This might be a key problem for many NMHSs in developing countries, hindering them to evolve to more objective impact-based warning systems.

Following Meteoalarm best practices, we recommend that NMHSs develop their user orientation and provide their public weather warnings in an impact-oriented format, i.e. starting easy through generic texts for impacts and advisories, and using the standardized Common Alerting Protocol (CAP). This, in combination with a subjective impact-based approach, e.g. using climatology-based thresholds with additional daily teleconferences with CPAs to jointly assess possible impact scenarios, can be a cost-efficient and effective way to start with. Moving on to more comprehensive impactbased production processes requires additional efforts, but can be based on the experiences of the first step. It is very important to involve CPAs and other key stakeholders (e.g. hydro service, avalanche service) from the beginning of the process and ensure continuous communication, cooperation and training. Understanding user needs and processes to improve service delivery are essential and require a paradigm change in many NMHSs; approved methods are described in WMO (2014) and Rogers et al. (2019).

Major gaps, preventing NMHSs to proceed towards IbW, can be identified in lack of: impact data, technical standards, cross-border exchange of impact data, impact-databases, verification methods, and resources. Further obstacles lie within legislative and organizational issues, cooperation with CPAs and other authorities and understanding of user (group) needs. Crowdsourcing is seen as an pragmatic and appropriate way to close the gap of "ground truth" and important for the verification of IoWs/IbWs. A recent survey on how crowdsourcing is used by European NMHSs was carried 
out by Krennert et al. (2018a). Especially real-time impactdata to "see what's happening out there" in order to adapt warnings in terms of a feedback loop is considered to be essential for operational meteorologists. Concepts like reporting apps using internationally standardized weather and impact reporting parameters (European Weather Observer; ESSL, 2020a) in combination with quality control through outreach and training via Trusted Spotter Networks (Krennert et al., 2018b) allow to tackle a number of the above listed gaps, while bridging the "last mile" of communication between operational meteorologists and the general public. Further, we recommend bringing together NMHSs and social scientists to work on topics like warning communication or risk perception (e.g. Weyrich et al., 2018, 2019; Potter et al., 2018), such as done in the WMO HIWeather Project (WMO, 2020a). Interdisciplinary research is needed as well to work on verification methods using crowdsourced, spatiotemporally nonhomogenous observations and to find verification measures for avoided losses. Knowledge transfer could be improved between identified (often hazard-driven) regional centers of competency. A marketplace concept for impact models and warning decision tools (e.g. car overturning model) could be established to avoid duplicated work.

In case of a cross-border high impact event, a majority of NMHSs want to get in touch with NMHSs or neighboring countries $24 \mathrm{~h}$ prior to the event using telephone or webbased chat-like tools. Regional projects, such as EUMETNET EMMA/Meteoalarm or WMO GMAS-Asia (WMO, $2020 \mathrm{~b}$ ) could leverage from these results to foster regional cooperation and information exchange among NMHSs.

The Common Alerting Protocol (CAP) is already a wellestablished standard in emergency alerting, which is requested by a growing number of initiatives and (global) reusers of authoritative warning information such as Google Crisis Response, IBM/The Weather Company, AccuWeather, MeteoGroup, and Windy.com (Sect. 1). However, NMHSs need to work together to adapt, harmonize and further refine their application of this standard for international hydrometeorological purposes. This would also make it easier for reusers to incorporate authoritative warning information into their products and services while crediting the source of information and thus raising the visibility of NMHSs. Both on a regional and global level, technical standards in the field of feedback from emergency services or impact databases need to be identified (such as EDXL-SitRep; OASIS, 2020b) or jointly created in collaboration with CPAs.

Last but not least it could be motivating to know for the students of meteorology interested in weather forecasting that forecast will most probably develop very much in the years to come, from a purely meteorological component to a wider field of other user perspectives as well, making this job more challenging and interesting than ever.
Data availability. Some of the participating NMHSs requested confidentiality about their answers. Therefore the dataset cannot be made publicly available. If you are interested in the questionnaire, please contact the main author.

Author contributions. RK drafted the questionnaire, carried out the survey and wrote the paper. AS and MS provided additional input, promoted the survey and reviewed the paper.

Competing interests. The authors declare that they have no conflict of interest.

Special issue statement. This article is part of the special issue "19th EMS Annual Meeting: European Conference for Applied Meteorology and Climatology 2019". It is a result of the EMS Annual Meeting: European Conference for Applied Meteorology and Climatology 2019, Lyngby, Denmark, 9-13 September 2019.

Acknowledgements. The authors would like to thank all Meteoalarm partners for participating in the survey and providing the requested information. Special thanks go to Eliot J. Christian for reviewing parts of this paper.

Review statement. This paper was edited by Haleh Kootval and reviewed by David Rogers and one anonymous referee.

\section{References}

Christian, E. J.: Report of the 2019 CAP Implementation Workshop, available at: https://www.preparecenter.org/sites/default/files/ cap-workshop-2019-report_1.pdf (last access: 24 April 2020), 2019.

Christian, E. J.: Filtered Alert Hub initiative, available at: https: //github.com/filtered-alert-hub/filtered-alert-hub/wiki/the-team, last access: 24 April 2020.

Dotzek, N., Groenemeijer, P., Feuerstein, B., and Holzer, A. M.: Overview of ESSL's severe convective storms research using the European Severe Weather Database ESWD, Atmos. Res., 93, 575-586, 2009.

Dupuy, C., Wai, H. G., Davidson, J., Staudinger, M., and Ismail, G.: Guidelines on International and Cross-border Collaboration in the Warning Process, PWS-22 WMO/TD No. 1560, available at: https://library.wmo.int/doc_num.php?explnum_id=9459 (last access: 24 April 2020), 2011.

ESSL: EWOB - European Weather Observer, available at: https: //www.essl.org/cms/european-severe-weather-database/ewob (last access: 24 April 2020), 2020a.

ESSL: European Severe Weather Database (ESWD), available at: https://www.essl.org/cms/european-severe-weather-database (last access: 24 April 2020), 2020b.

EUMETNET: EMMA, available at: https://www.eumetnet.eu/ activities/forecasting-programme/current-activities-fc/emma (last access: 24 April 2020), 2020a. 
EUMETNET: Meteoalarm, available at: https://www.meteoalarm. eu (last access: 24 April 2020), 2020 b.

Krennert, T., Pistotnik, G., Kaltenberger, R., and Csekits, C.: Crowdsourcing of weather observations at national meteorological and hydrological services in Europe, Adv. Sci. Res., 15, 7176, https://doi.org/10.5194/asr-15-71-2018, 2018a.

Krennert, T., Kaltenberger, R., Pistotnik, G., Holzer, A. M., Zeiler, F., and Stampfl, M.: Trusted Spotter Network Austria - a new standard to utilize crowdsourced weather and impact observations, Adv. Sci. Res., 15, 77-80, https://doi.org/10.5194/asr-1577-2018, 2018b.

OASIS: Common Alerting Protocol Version 1.2. OASIS Standard, available at: http://docs.oasis-open.org/emergency/cap/v1. 2/CAP-v1.2-os.html (last access: 29 February 2020), 2020a.

OASIS: OASIS Emergency Management TC, available at: https://www.oasis-open.org/committees/emergency (last access: 24 April 2020), 2020b.

Potter, S. H., Kreft, P. V., Milojec, P., Noble, C., Montz, B., Dhellemmes, A., Wood, R. J., and Gauden-Ing, S.: The influence of impact-based severe weather warnings on risk perceptions and intended protective actions, Int. J. Disast. Risk Reduct., 30, 34 43, https://doi.org/10.1016/j.ijdrr.2018.03.031, 2018.

Rogers, D. P., Tsirkunov, V. V., Kootval, H., Soares, A., Kull, D., Bogdanova, A. M., and Suwa, M.: Weathering the Change: How to Improve Hydromet Services in Developing Countries?, The World Bank, Washington, 2019.

Tong, Y. F. and Cheng, Y. C. A.: Warnings on Tropical Cyclone for WMO Global Multi-Hazard Alert System, Trop. Cyclon. Res. Rev., 7, 230-236, https://doi.org/10.6057/2018TCRR03.06, 2018.

United Nations: Sendai Framework for Disaster Risk Reduction 2015-2030, available at: https://www.undrr.org/publication/ sendai-framework-disaster-risk-reduction-2015-2030 (last access: 24 April 2020), 2015.

Weyrich, P., Scolobig, A., Bresch, D. N., and Patt, A.: Effects of impact-based warnings and behavioral recommendations for extreme weather events, Weather Clim. Soc., 10, 781-796, https://doi.org/10.1175/WCAS-D-18-0038.1, 2018.
Weyrich, P., Scolobig, A., and Patt, A.: Dealing with inconsistent weather warnings: Effects on warning quality and intended actions, Meteorol. Appl., 26, 569-583, https://doi.org/10.1002/met.1785, 2019.

WMO: Resolution 40 (CG-XII): WMO policy and practice for the exchange of meteorological and related data and products including guidelines on relationships in commercial meteorological activities, available at: https://www.wmo.int/pages/prog/www/ois/Operational_ Information/Publications/Congress/Cg_XII/res40_en.html (last access: 24 April 2020), 1995.

WMO: The WMO Strategy for service delivery and its implementation plan, WMO-No. 1129, available at: https://library.wmo.int/ doc_num.php?explnum_id=7854 (last access: 24 April 2020), 2014.

WMO: WMO Guidelines on Multi-Hazard Impact-Based Forecast and Warning Services, WMO-No. 1150, available at: https: //library.wmo.int/doc_num.php?explnum_id=7901 (last access: 24 April 2020), 2015.

WMO: World Meteorological Congress, Abridged Final Report of the Eighteenth Session, Geneva, 3-14 June 2019, WMONo. 1236, available at: https://library.wmo.int/doc_num.php? explnum_id=9827\#page=69 (last access: 24 April 2020), 2019.

WMO: The High-Impact Weather Project (HIWeather), available at: http://hiweather.net (last access: 24 April 2020), 2020a.

WMO: WMO Pilot Project to Enhance the Capability of Meteorological Disaster Risk Reduction in RAII (Asia) (GMAS-A), available at: https://gmas.asia (last access: 24 April 2020), 2020b.

WMO: Severe Weather Information Centre 2.0 (Beta), available at: https://severeweather.wmo.int/v2/index.html (last access: 24 April 2020), 2020c.

WMO: WMO Register of Alerting Authorities, available at: https: //alertingauthority.wmo.int/ (last access: 24 April 2020), 2020d. 